ARCHIVO ESPAÑOL DE ARTE, LXXXVIII, 351

JULIO-SEPTIEMBRE 2015, pp. 299-303

ISSN: 0004-0428, eISSN: 1988-8511

doi: 10.3989 /aearte.2015.18

\title{
VARIA
}

\section{LUCA CAMBIASO: NUEVOS DATOS SOBRE SUS HEREDEROS}

\author{
José Luis Cano de Gardoqui García \\ Universidad de Valladolid
} Documentos de pago a favor de Orazio Cambiaso, hijo del pintor Luca Cambiaso, activo en El Escorial entre 1583
y 1585, prueban la renuncia de Laureta, hija de Luca, al dinero procedente de atrasos por ejecución de pinturas y nó-
minas del Maestro, que ésta habría de cobrar en calidad de su heredera.

Palabras clave: Luca Cambiaso; Orazio Cambiaso; Laureta Cambiaso; Monasterio de El Escorial.

\section{LUCA CAMBIASO: NEW DATA CONCERNING HIS HEIRS}

Payment documents in favor of Orazio Cambiaso, son the painter Luca Cambiaso, active in El Escorial between 1583 and 1585, demonstrate that Lauretta, daughter of Luca, renounced money owed to her father for the execution of paintings and arrears from his pay that she was entitled to as his heir.

Key words: Luca Cambiaso; Orazio Cambiaso; Laureta Cambiaso; Monastery of El Escorial.

Resultan sobradamente conocidas para la historiografía artística las circunstancias vitales y profesionales del pintor genovés Luca Cambiaso (1527-1585) - llamado en España «El Luqueto»-, desde sus inicios como ayudante en el taller paterno, pasando por la fama obtenida como fresquista en su ciudad natal, hasta su llegada a España en octubre de 1583, junto a su hijo, el también pintor Orazio, a su discípulo Lázaro Tavarone y a los escultores y entalladores, padre e hijo, Gaspare y Andrea de Lucca, con destino a la decoración de las grandes superficies murales del Monasterio de El Escorial. Allí fallecería Luca, el 5 de septiembre de 1585, siendo enterrado en la parroquia de San Bernabé de dicha localidad ${ }^{1}$. Es, pues, difícil hallar, por lo que se refiere en concreto a la abundante docu-

\footnotetext{
${ }^{1}$ Para la biografía y catálogo de Luca Cambiaso continúa siendo fundamental el libro de Suida Manning/Suida, 1958. A esta obra hay que añadir una anterior de Zarco, 1932: 1-27, que aporta interesante documentación procedente del Archivo de la Real Biblioteca del Monasterio de El Escorial en relación con las libranzas de pago a favor de Cambiaso por la realización de diversas pinturas para el Monasterio, con la propias pinturas, así como noticias de los salarios devengados al artista. Para nuevos datos relacionados con Luca, Andrés, 1972-1977: 1-307.Nuevos e importantes datos, Marías, 1979: 83-86. Así también, López Torrijos, 1987: 243-248. Recopilación e investigación sobre Cambiaso en el contexto general de la decoración
} 
mentación generada durante el proceso constructivo y decorativo de El Escorial, algún dato inédito de la suficiente relevancia que permita añadir algo más a la biografía de Cambiaso.

Tanto las libranzas a pintores registradas por el pagador de la fábrica de El Escorial, Tomás de Paz, entre 1583 y 1586, existentes en el Archivo General de Simancas ${ }^{2}$, como la documentación procedente del Archivo de la Real Biblioteca del Monasterio de El Escorial, utilizada por Zarco Cuevas en su obra de referencia ${ }^{3}$, apenas ofrecen variaciones significativas por lo que respecta a los datos relativos a ejecución de pinturas, cantidades percibidas por dicha actividad o el salario anual de 500 ducados que Cambiaso recibe por tercios de 62.5000 maravedíes cada uno de ellos.

Sin embargo, ambas fuentes documentales -Escorial y Simancas- registran ciertas libranzas a favor del hijo de Luca, el también pintor Orazio Cambiaso, y de los hermanos de éste, fechadas en noviembre de 1586, es decir, un año después de la muerte del maestro. Estas libranzas, si bien resultan bastante similares respecto a sus referencias acerca de, por ejemplo, cantidades de dinero adeudadas a Luca por la realización de ciertas pinturas murales para El Escorial (Coro, Escalera Principal, etc.), difieren en la presencia de una serie de añadidos en sus textos, los cuales permiten clarificar algunos extremos y dudas planteados por Marías respecto al postrer testamento y herencia de Cambiaso; en particular, la necesidad de confirmar la autenticidad del último testamento otorgado por Luca el 5 de septiembre de 1585, confirmación solicitada por Orazio Cambiaso más de un año después, el 9 de octubre de $1586^{4}$.

Existe particularmente un documento de libranza, publicado por Zarco y, más tarde recogido por Suida ${ }^{5}$, fechado el 30 de noviembre de 1586, y similar al escrito en las cuentas del pagador Tomás de Paz ${ }^{6}$, consistente en una nota de pago a Orazio Cambiaso y a Juan Jacome de Grimaldo, representante de los hermanos de Orazio en calidad de herederos del padre: Pomponio, Aurelio, Esteban, Octavio y Juan Bautista Cambiaso, donde se registra la cobranza de una suma total de 63.270 reales por diez libranzas extendidas entre junio de 1584 a agosto de 1585 , y que corresponden a la ejecución por parte de Luca Cambiaso de la pintura de la bóveda del coro de la Basílica de El Escorial, la pintura de la capilla del Altar Mayor y la de la Escalera Principal del Monasterio. En dicha libranza aparece la siguiente nota añadida en su margen: "Conforme al testamento del mastre Lucas, paresçió hauer vn heredero más, y por hauer sido informado que éste fué dotado y tener resçebido su parte de la herençia, se le hizo escriptura de fiança para que no se pedirá de su parte cosa alguna. Pidióla el contador. Thomás de Ayardi, y entregósele para poner en sus libros".

Nada se dice aquí acerca de la identidad del nuevo heredero ${ }^{7}$. Sin embargo, basta comparar el listado de los herederos de Luca incluidos en sus dos primeros testamentos, otorgados respectivamente el 18 de abril de 1582 y el 27 de septiembre de $1583^{8}$, con los nombres de los herederos

de la Basílica del Monasterio de El Escorial, Mulcahy, 1992: 81-110.Más reciente y exhaustivo es el catálogo de la exposición celebrada en Génova entre el 3 de marzo y el 8 de julio de 2007, que realiza un recorrido por la vida y la obra del artista, contando con destacadas contribuciones a cargo de Lauro Magnani, Piero Boccardo, entre otros especialistas, así como la de Carmen García-Frías centrada en la presencia de Cambiaso en España, los frescos de El Escorial y la personalidad y trayectoria de los discípulos y ayudantes del maestro tras su fallecimiento, Boccardo/Bober, 2007.

2 Archivo General de Simancas (AGS), sección Contaduría Mayor de Cuentas (CMC) $1^{\text {a }}$ época, legajo 1760, y CMC $2^{a}$ época, legajos 391 y 383 . Aquí interesa particularmente el legajo 1760 con las «datas» correspondientes a pintores activos en la fábrica de El Escorial y las relativas al capítulo de nóminas de los oficiales pintores del Monasterio.

3 Zarco, 1932: 1-27.

${ }^{4}$ Marías, 1979: 85.

${ }^{5}$ Zarco, 1932: 25-26. Suida Manning/Suida, 1958: 230-231.

${ }^{6}$ El dicho pagador Tomás de Paz. La dicha su datta de marauedies pagados a pintores, s.f., AGS, sección CMC $1^{\text {a }}$ época, legajo. 1760 .

${ }^{7}$ Zarco, 1932: 13-14. El autor piensa que este personaje podría haber sido Andrea de Lucca, el «hijo» del escultor y entallador Gaspare de Lucca, ambos llegados a España en compañía de Luca Cambiaso.

${ }^{8}$ Suida Manning/Suida, 1958: 232-234. Marías, 1979: 83.

Arch. esp. arte, LXXXVIII, 351, JULIO-SEPTIEMBRE 2015, 299-303 ISSN: 0004-0428, eISSN: 1988-8511, doi: 10.3989/aearte.2015.18 
del último testamento de 5 de septiembre de 1585, para comprobar la presencia en este último de un hijo más del maestro, en este caso una hija, Laureta, casada en Génova con Jacome Bernardi, a la que, además de la cantidad de 25 escudos, Luca le deja lo correspondiente al reparto de la herencia entre el resto de hermanos ${ }^{9}$.

La sorprendente inclusión de Laureta como heredera suscitó, como indican los documentos de Simancas, una serie de requisitorias por parte de la Congregación del Monasterio de El Escorial ante la idea de entregar el dinero adeudado a Luca por este y otros conceptos a más herederos de los pensados en un principio, teniendo en cuenta además que el último testamento del Maestro había sido otorgado el día anterior a su muerte.

Así las cosas, aunque Orazio Cambiaso y Juan Jacome de Grimaldo llegaron a aseverar ante la Congregación que Laureta no había de tener parte alguna "de la dicha herençia, porque tiene rresçiuido y está doctada en más cantidad de lo que le pudiera perteneçer de estos uienes y herençia del dicho maestre Lucas" $"$, la Congregación ya habría solicitado de Orazio no sólo la confirmación de la autenticidad del último testamento, sino también una escritura de fianza y obligación por parte de Juan Jacome de Grimaldo, de fecha de 28 de noviembre de 1586, por la que, dudando la Congregación de que Grimaldo tuviera el poder de Laureta, ésta se obligaba a renunciar a percibir o reclamar su parte en dicha herencia ${ }^{11}$.

En efecto, las cuentas del pagador de la fábrica de El Escorial, Tomás de Paz, del año de 1586 contienen interesantes comentarios e informes al respecto que, sin duda, clarifican las cuestiones aquí planteadas. De un lado, en la "Data de marauedíes pagados a pintores", la comentada libranza publicada por Zarco a favor de Orazio, y relativa a la ejecución de diversas pinturas en el Monasterio por parte de Luca, presenta el siguiente añadido: "Y porque el dicho Maestre Lucas dexó entre otros herederos a Laureta, su hija, muger de Jacome Bernardi residente en Génova, de quien no traxeron poder para la dicha cobrança, la dicha Congregaçión acordó se les entregase la parte que le tocaua, haciendo el dicho Jacome de Grimaldo obligaçión de que estaua pagada la dicha Laureta de la parte que auía de auer de la herençia del dicho su padre en el dote que se le haya dado, el qual se obligó a ello y de que serían bien pagados y no los pedirían en ningúnd tiempo, la qual quedó en la data de salarios de esta quenta"12.

Por otra parte, en la data del pagador Tomás de Paz relativa a los salarios percibidos por los oficiales de la fábrica de El Escorial, aparece otra libranza, también de 30 de noviembre de 1586, a favor de Orazio Cambiaso, "hijo y heredero del maestre Lucas Cambiaso"... y de Juan Jacome de Grimaldo, por poder de Pablo Canbrasio y Rafael de Nobis, tutores y curadores de Ponponio y Abrelio Canbrasio, hijos del dicho maestre Lucas y de los demás sus hijos y herederos". Esta nota de pago alcanza en este caso la cantidad de 65.106 maravedíes, correspondientes a los atrasos en la percepción del salario mensual de Luca, de 500 ducados, comprendidos desde el 1 de mayo de 1585 hasta el 5 de septiembre del mismo año, en que falleció. Cabe señalar que el texto añadido a esta libranza, referido a la renuncia por parte de Laureta y Grimaldo de la cantidad que correspondería a la hija como heredera por dicho concepto, resulta enteramente igual al de la libranza anterior.

Finalmente, en el mismo legajo, pocos pliegos más allá de estas notas de pago, se encuentra la escritura de fianza y obligación suscrita por Grimaldo acerca de la renuncia de Laureta a la herencia dejada por su padre en su testamento ${ }^{13}$. En este documento, fechado el 28 de noviembre de

\footnotetext{
${ }^{9}$ Marías, 1979: 84

${ }^{10}$ AGS, sección CMC 1a época, leg. 1760, s.f. Véase Apéndice Documental.

11 Véase Apéndice Documental.

${ }^{12}$ El dicho pagador Tomás de Paz. La dicha data de marauedies pagados a los ofiçiales de la dicha fábrica de sus salarios del año de 1586, s.f., AGS, sección. CMC 1ª́poca, legajos. 1760.

13 Véase Apéndice Documental.
}

Arch. esp. arte, LXXXVIII, 351, JULIO-SEPTIEMBRE 2015, 299-303

ISSN: 0004-0428, eISSN: 1988-8511, doi: 10.3989/aearte.2015.18 
1586, dos días anterior, por tanto, a las citadas libranzas, se explicitan las dudas de la Congregación monasterial ante los pagos que debía efectuar a los herederos de Luca Cambiaso, las razones que movieron a Orazio a solicitar la autentificación del testamento del padre, así como las opiniones que Orazio y Grimaldo sostuvieron ante las «pretensiones» de Laureta, al menos las derivadas de su inclusión en el testamento de 1585.

Si bien los documentos aquí publicados no cambian de forma sustancial lo que desde muchos años atrás se ha venido investigando y aportando a la vida y obra de Luca Cambiaso, sí, por el contrario, pueden enriquecer y completar la biografía de un destacado artista, activo en España a finales del siglo XVI en el ámbito de las Obras Reales.

\section{APÉNDICE DOCUMENTAL}

El dicho pagador Tomás de Paz. Obligaçión que hizo Juan Jacome de Grimaldo de que hera bien pagada la parte que Laureta, hija de maestre Lucas, ubo de aver de dos libranças que se libraron a los herederos del dicho maestre Lucas.

En la uilla de Madrid, a ueinte y ocho días del mes de nouiembre de mill y quinientos y ochenta y seis años, ante mí el escribano y testigos yusoscriptos pareçió presente Juan Jacome de Grimaldo, hijo de Juan Uaptista difunto rresidente en la dicha uilla de Madrid, e dixo que por quanto en el testamento e última uolumtad que Mastre Lucas Cambiasso, pintor de Su Magd., hizo y otorgó estando enfermo en el sitio del Monasterio de San Lorençio el rreal en el mes de septiembre del año pasado de quinientos y ochenta y çinco de la enfermedad de que murió, demás de auer nombrado por sus hijos y herederos a Oraçio Cambrasio, residente en la dicha fábrica del dicho Monasterio, y a otros çinco sus hijos, nombró y dexó por heredera a Laureta, su hija, muger de Jacome de Bernardi, rresidente en Génoua. Y abiéndose pedido a los señores de la Congregaçión de la dicha fábrica la cobrança y paga de dos mill y seteçientos y setenta reales, que montan nouenta y quatro mill y çiento y ochenta marauedíes que se rrestaron deuiendo al dichomaestre Lucas de las pinturas que hizo en el dicho Monesterio e yglesia prinzipal de él, conforme a las tasaçiones que de la dicha pintura fueron hechas, y más sesenta y çinco mill y çiento y seis marauedíes de la rrata del salario que se le deuía al dicho maestre Lucas desde primero de mayo del dicho año de ochenta y çinco hasta çinco de septiembre siguiente del dicho año que murió a rrazón de quinientos ducados que tenía de salario al año por su asystençia, demás de la paga de sus obras, se a dudado en que el dicho Juan Jacome de Grimaldo, aunque tiene poder de los demás hijos y herederos del dicho maestre Lucas, no lo tiene de la dicha Laureta, hija del maestre Lucas, ny de su marido. Y no embargante que se a rrespondido de parte de los dichos Oraçio Cambrasio y Juan Jacome de Grimaldo que la susodicha no a de auer parte alguna de la dicha herençia, porque tiene rresçiuido y está doctada en más cantidad de los que le pudiera perteneçer de los dichos uienes y herençia del dicho maestre Lucas, su padre, se les a pedido que den seguridad de que no será pedido ny demandada cosa alguna de los marauedíes que dicho es que se rrestaron deuiendo al dicho maestre Lucas y que son bien pagados al dicho Oraçio Cambiasio y al dicho Juan Jacome de Grimaldo en nombre de los demás hijos y herederos del dicho maestre Lucas por uirtud del poder que tiene presentado. Por tanto dixo que se obligaba e obligó y aseguraba y aseguró la paga de los dichos marabedíes ser bien pagados a los dicho Oraçio Cambiaso y al dicho Juan Jacome de Grimaldo en el dicho nombre, y que no serán pedidos ni demandada parte alguna de los dichos marauedís por la dicha Laureta ny su marido ny por otra persona alguna en su nombre por raçón de la dicha herencia, ny en otra manera alguna a los dichos señores de la Congregación, ny al dicho pagador de la dicha fábrica, ny otra persona alguna, so pena de boluer y rrestituyr la parte que pidieren y les perteneçiere de los dichos marauedíes que an y se le libran y pagan de presente y que son en las dichas dos

Arch. esp. arte, LXXXVIII, 351, JULIO-SEPTIEMBRE 2015, 299-303 ISSN: 0004-0428, eISSN: 1988-8511, doi: 10.3989/aearte.2015.18 
partidas çiento y çinquenta y nueue mill y dozientos y ochenta y seis marauedíes, los quales se pagan por el pagador de la dicha fábrica y con las costas y daños que sobre ello se les siguieren y rrecresçieren, haziendo como hizo para este efeto de deuda agena suya propia. Para lo qual ansy cumplir, obligó su persona y uienes auidos y por auer, y dió poder cumplido a todas y qualesquier juezes y justiçias de Su Magd. de qualesquier partes que sean, a cuya juridiçión se sometió y rrenunçió su propio fuero y juridiçión y domiçilio, y la ley sit conuenerit de jurisdictione omnium judicum, para que por todo rremedio y rrigor de derecho y uía executiba le compelam y apremien a la paga y cumplimiento de lo que dicho es, como y ansy fue sentençiado por juez competente y por él consentida y pasada en cosa juzgada y rrenunçiamiento todas y qualesquier leyes, fueros y derechos que sean en su ffavor, y la ley y derecho que dize que general rrenunçiaçión de leyes. Fecha non uala. Testigos que fueron presentes: Otabio de Marín y Juan Bautista de Andrada y Lope Ortiz, estantes en esta Corte. Y el dicho otorgante al cual yo, el presente escriuano, doy fee que conozco, lo firmó de su nombre en el registro. Juan Jacome Grimaldo. Ba entre reenglones, los quales se pagan. E yo, Pablo Quadrado, scriuano público del Rey nuestro señor, resydente en su Corte y natural del lugar del Espinar, pressente fui al otorgamiento de esta escriptura con los dichos testigos y otorgante, que en mi rregistro firmó su nombre, e ize mi signo (Signo) en testimonio de verdad.

Pablo Quadrado

Fiança y obligaçión que hizo Juan Jacome de Grimaldo de que no se pedirá por uno de los hijos y herederos de mastre Lucas cosa alguna de lo que se libró a los demás.

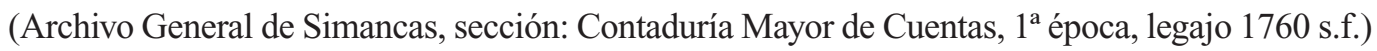

\section{BIBLIOGRAFÍA}

Andrés Martínez, Gregorio de (1972-1977): "Inventario de documentos sobre la construcción y ornato del Monasterio de El Escorial existentes en el Archivo de su Real Biblioteca", anejo de Archivo Español de Arte. Madrid, pp. 1-307.

Boccardo, Piero / Bober, Jonathan (eds.) (2007): Luca Cambiaso, un maestro del Cinquecento europeo, Catalogo della mostra (Genova, 3 marzo-8 luglio). Milano.

López Torrijos, Rosa (1987): "Documentos genoveses para la venida de Luca Cambiaso a España”. En: Real Monasterio-Palacio de El Escorial. Estudios inéditos en el IV centenario de la terminación de las obras. Madrid, pp. 243-248.

Marías, Fernando (1979): "Luca Cambiaso: Testamento escurialense e inventario de bienes". En: Archivo Español de Arte, n. 205. Madrid, pp. 83-86.

Mulcahy, Rosemarie (1992): La decoración de la Real Basílica del Monasterio de El Escorial. 'A la mayor gloria de Dios y el Rey'. Madrid, pp. 81-110.

Suida Manning, Bertina / Suida, Wilhelm Emil (1958): Luca Cambiaso, la vita e le opere, Milano.

Zarco Cuevas, Julián (1932): Pintores italianos en San Lorenzo el Real de El Escorial (1575-1613). Madrid, pp. 1-27.

Fecha de recepción: 20-V-2014

Fecha de aceptación: 10-X-2014

Arch. esp. arte, LXXXVIII, 351, JULIO-SEPTIEMBRE 2015, 299-303

ISSN: 0004-0428, eISSN: 1988-8511, doi: 10.3989/aearte.2015.18 